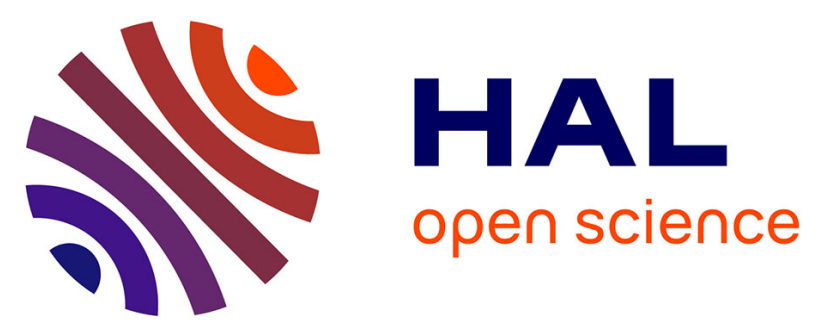

\title{
SEDIMENTARY RECORDS OF REVERSAL TRANSITIONS -MAGNETIZATION SMOOTHING ARTEFACT OR GEOMAGNETIC FIELD BEHAVIOUR?
}

R. Weeks, M. Fuller, C. Laj, A. Mazaud, E. Herrero-Bervera

\section{To cite this version:}

R. Weeks, M. Fuller, C. Laj, A. Mazaud, E. Herrero-Bervera. SEDIMENTARY RECORDS OF REVERSAL TRANSITIONS -MAGNETIZATION SMOOTHING ARTEFACT OR GEOMAGNETIC FIELD BEHAVIOUR?. Geophysical Research Letters, 1992, 19 (20), pp.2007-2010. 10.1029/92gl02140 . hal-03584179

\author{
HAL Id: hal-03584179 \\ https://hal.science/hal-03584179
}

Submitted on 22 Feb 2022

HAL is a multi-disciplinary open access archive for the deposit and dissemination of scientific research documents, whether they are published or not. The documents may come from teaching and research institutions in France or abroad, or from public or private research centers.
L'archive ouverte pluridisciplinaire HAL, est destinée au dépôt et à la diffusion de documents scientifiques de niveau recherche, publiés ou non, émanant des établissements d'enseignement et de recherche français ou étrangers, des laboratoires publics ou privés. 


\title{
SEDIMENTARY RECORDS OF REVERSAL TRANSITIONS - MAGNETIZATION SMOOTHING ARTEFACT OR GEOMAGNETIC FIELD BEHAVIOUR?
}

\author{
R. Weeks ${ }^{1}$, M. Fuller ${ }^{2}$, C. Laj ${ }^{1}$, A. Mazaud ${ }^{1}$, E. Herrero-Bervera ${ }^{3}$
}

\begin{abstract}
Sedimentary records of reversals for the past 12 million years exhibit preferred longitudes of their VGP paths. This observation may be related to long term aspects of coremantle dynamics. However, it has been suggested that sedimentary VGP paths could be an artefact due to smoothing which mixes non antipodal pre- and post-transitional directions. We show here that smoothing over unrealistically long time scales is required to generate intermediate directions of magnetization which are purely mixtures of pre- and posttransitionals directions in sediments whose remanence is primarily depositional (DRM) or post-depositional remanence (PDRM). Sedimentary records of transitions showing VGP paths confined to the planes of immediately pre- and posttransitional VGPs have however been observed. These can be explained by non-axisymmetric bias in the non-reversing field [Gubbins and Bloxham, 1987; Constable, 1992], which plays a role in reversals. Therefore, provided that magnetization directions are properly cleaned to give single component directions, the preferential longitudes of reversal VGP paths will be due to field behaviour and not to an artefact of the magnetization process. If, however, mixtures of primary magnetization acquired at the time of the formation of the rock and secondary magnetization acquired later are measured, then artefacts will be generated.
\end{abstract}

\section{Introduction}

In the preceeding letter [Laj et al., this volume], we have argued that transitional VGP paths for reversals during the past 12 million years are preferentially located in a longitude band over the Americas and to a lesser extent in the antipodal longitudes over eastern Asia. This structure could reveal major aspects of core-mantle dynamics [Laj et al., 1991] and therefore is of considerable potential importance.

In a recent paper, Constable [1992] has shown that the VGP paths over the Americas are consistent with a reversal brought about by decay and subsequent recovery of the present axial field. This is of course, as she notes, a direct consequence of the present VGP lying in the longitude over the Americas, which is in turn principally due to the orientation of the equatorial dipole. As the axial dipole decreases, the location of the VGP is increasingly controlled by the equatorial dipole which maintains the path over the Americas. This result shows that, given the present field, we would expect reversal paths over the Americas, as has been observed.

\section{1 - Centre des Faibles Radioactivités, CEA-CNRS, Gif-sur- Yvette, France \\ 2 - University of California Santa Barbara, USA \\ 3 - University of Hawaii, USA}

Copyright 1992 by the American Geophysical Union.

Paper number 92GL02140

0094-8534/92/92GL-02140\$03.00
Constable has also demonstrated that the non-transitional volcanic data available for the last 5 million years document a non-zonal bias, similar to that observed in reversal sedimentary records, even after correcting for the inhomogeneous distribution of sampling sites. It therefore appears that the asymmetries in the present field noted by Gubbins and Bloxham [1987] and Constable [1992] are relatively long lived features of the field and could also control the reversal VGP paths.

The fidelity of sedimentary records of reversals has, however, often been questioned [Larson and Walker, 1982, 1985; Rochette, 1990; van Hoof and Langereis, 1991]. Recently, Langereis et al. [1992] demonstrated that the VGP paths for the majority of the sedimentary records from Southern Italy and Greece lie in the plane defined by nonantipodal pre- and post-tansitional VGPs.

Two extreme possibilities have to be considered. First, the two preferred longitudinal bands of transitional VGP's truly reflect some aspect of the reversal transitional field. Second, sedimentary records of reversals mostly result from strong smoothing and are simply great circles joining pre- and posttransitional directions.

In this letter we attempt to take a critical look at smoothing in the recording of geomagnetic field behaviour during reversals in sedimentary records. In attempting to recover variations of the field on the time scale of hundreds, or thousand years paleomagnetists approach the limits of the paleomagnetic technique. Nevertheless, the records of the secular variation from lake and ocean sediments [e.g. Creer and Tucholka, 1982; Tric et al., 1992] strongly suggest that some impression of field variations on this time scale can be achieved.

One has to consider separately records which can be shown to be carried by depositional (DRM) or postdepositional (PDRM) remanent magnetization, and records in which the chemical environment of the sediment changes in such a way that the original detrital minerals are destroyed, or modified, and new magnetic phases are created, which carry natural remanent magnetization (NRM).

For the first case, one can suggest limits on time constants and possible effects of the smoothing process. As might be expected, it is the relation of the smoothing time constant to the inherent time constants of the transitional field behaviour, which is important. Smoothing on a time scale short compared with a reversal transition inevitably plays a role in reversal records. However, smoothing on time scales longer than the transition is probably less important in the relatively high sedimentation rate sections used for reversal studies.

For the second case, which involves secondary magnetizations of authigenic phases, the analysis is much more difficult and it is not clear that we can expect to recover useful records of the field behaviour [van Hoof and Langereis, 1991; Langereis et al., 1992].

Here we consider primarly the first case with particular attention to the intriguing result of Langereis et al. [1992] that the VGP paths are related to asymmetries in the field before 
and after the reversal. An interpretation is offered based upon simple transition models which only requires that the dipole field decays without major directional changes in the early stages of the reversal.

\section{Smoothing of sedimentary records carrying DRM or PDRM}

Rochette [1990] proposed that the acquisition time of the magnetization of intrusions and some sediments recording transitional fields may be long compared with the time taken for the field to reverse. Therefore the directions recorded are simply combinations of differing proportions of normal and reversed components of magnetization, acquired before and after the reversal. If the VGP's before and after the reversal are not antipodal, then a longitudinally confined path will be defined. The contention is that such smoothing, with the additional factor of non-antipodal VGP's before and after the reversal, can explain the records and in particular the preponderance of VGP paths at certain longitudes.

The key factor in Rochette's approach is that no true transitional directions are recorded - the field is held to "take an instantaneous jump from the normal to the reverse state". While this is justified if the smoothing took place over times very long compared to the reversal time, in the general case it is more accurate to think of the resulting record as the convolution of the geomagnetic field variation, including intermediate directions, with the smoothing function of the sedimentary magnetization process.
If intermediate directions are included as part of the signal, a very different situation is generated. In Figure $1 \mathrm{a}-\mathrm{b}$, we illustrate the effect of smoothing over a model field reversal which includes intermediate directions. The true transitional VGP path is chosen to lie perpendicular to the plane defined by a non-antipodal bias in the post-transitional field. The bias should then deflect the true VGP path towards the plane of the non-antipodal bias. Complete dominance of the non-antipodal bias would result in a path perpendicular to the true path. The smoothing function which is convolved with the model signal is shown in Figure 1c. The smoothing deflects the path half way between the true path and the path determined by the non-antipodal bias (Figure $1 b$ ). This roughly illustrates the situation in which the intermediate direction and the bias have equal effects on the transition path. The width at mid-height of the smoothing function is four to five times the width of the polarity transition. This single example is an arbitrary choice, although it does have some special relevance for the European sites which are at $90^{\circ}$ from the preferred longitudes. Nevertheless, it is very clear that for complete control by the bias, so that the directions completely collapse onto the plane of the non-antipodal bias, much heavier smoothing is required.

To explain the records from sediments carrying DRM, or PDRM, by Rochette's mechanism the magnetization must be acquired over a sufficiently long time before and after the actual reversal for virtually all traces of the intermediate field to be lost, say several tens of thousands of years. At
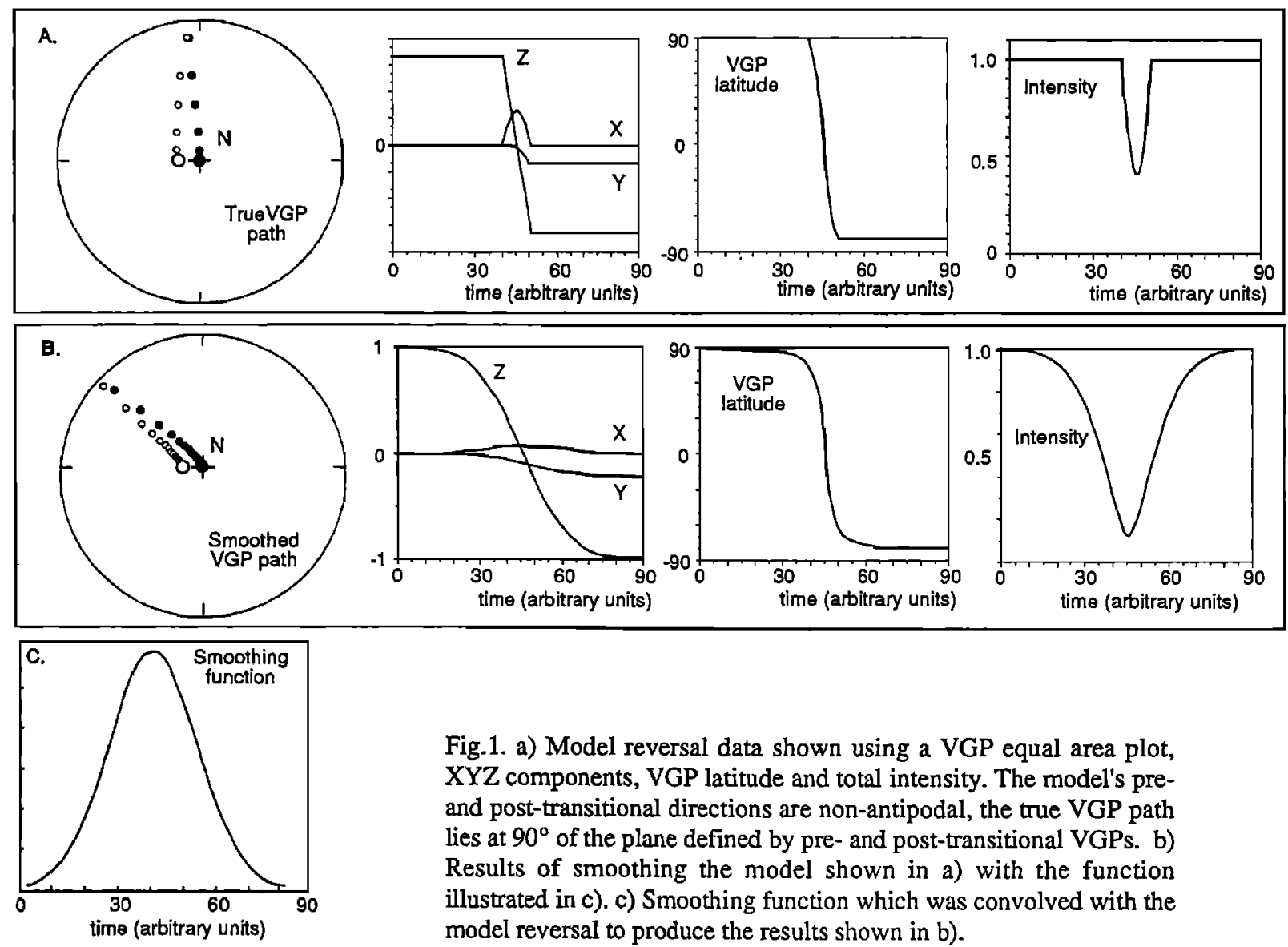

Fig.1. a) Model reversal data shown using a VGP equal area plot, $X Y Z$ components, VGP latitude and total intensity. The model's preand post-transitional directions are non-antipodal, the true VGP path lies at $90^{\circ}$ of the plane defined by pre- and post-transitional VGPs. b) Results of smoothing the model shown in a) with the function illustrated in c). c) Smoothing function which was convolved with the model reversal to produce the results shown in b). 
sedimentation rates of between 5 and $10 \mathrm{~cm} / \mathrm{kyr}$, smoothing would be required over several meters of sediment.

Several features of sedimentary records appear to indicate that this amount of smoothing is, in the general case, not realistic. For instance, marine cores from the Mediterranean have been shown to record geomagnetic field intensity variations on a time scale of less than 5000 years, and these variations perfectly correlate with results from volcanic formations which are devoid of smoothing phenomena [Tric et al., 1992].

In the Mediterranean area, marine records of the Blake event [Creer et al., 1980; Tric et al., 1991], show the same double event in correlatable fine structure, which is also observed in lacustrine records from Oregon with a much higher sedimentation rate [Herrero-Bervera et al., 1989]. Close examination of these records suggests while the field does achieve a full reversal, the VGP passes through the reverse state without significant delay. Moreover, the onset path from normal to reverse is quite different from the return path to normal polarity. Hence smoothing must be on a time scale considerably shorter than half of the event length, which is estimated to be about 5000 years [Tric et al., 1991].

In the records of the Cobb event described by Clement and Martinson [1992], particularly convincing fine structure has been demonstrated which is coherent over a distance of 1300 $\mathrm{km}$. The coherence of this fine structure between different records cannot be random noise and suggests that smoothing is on time scales considerably less than half the event time, probably less than a thousand years.

All these observations clearly indicate that smoothing on very long time scales may be unrealistic in the general case, so that Rochette's mechanism cannot be considered as a general explanation for reversal paths. An additional problem with the long term smoothing model is that the intensity curve has a characteristic inverted cuspate form which is not seen in the observed records.

\section{Discussion}

Despite the evidence that Rochette's initial model cannot explain the reversal paths, Langereis et al. [1992] have provided directional data which are, in some aspects, consistent with this idea and these must be explained. As mentioned above, these workers demonstrated that the VGP path for the majority of the sedimentary records from Southem Italy and Greece lie in the plane defined by nonantipodal pre- and post-transition VGP's. The agreement between the paths and the plane defined by immediate preand post-transition VGP's appeared to be significantly better than that between the VGP paths and the planes defined by stable VGP's established for times far from the reversals.

Following the results of Constable [1992], the simplest explanation recognizes that there are asymmetries in the transitional field which are related to asymmetries in the non transitional fields. Thus the preferred longitudes in transitional VGP paths and non-reversing VGP's are both due to asymmetries of the field and have nothing to do with smoothing.

Sedimentary records clearly do involve some smoothing of the field behaviour. So we now consider the effect of smoothing in the framework of the explanation just given. In this case, the dipole field controls the locally observed direction, in the stable non-reversing field, so strongly that, until there is a major decrease in the dipole moment, no significant directional change appears. Only when the dipole field intensity becomes comparable to that of the transitional field, does the VGP depart gradually from its non-reversing location. Then, the movements from this VGP location, across the equator to a corresponding location in the opposite hemisphere is relatively rapid, with the dipole field close to its minimum value. This is followed by gradual movement to the new non-reversing location. The behaviour is then a very slow departure from stable polarity, a comparatively rapid equatorial crossing at weak fields and a slow recovery of the new stable polarity. During the relatively rapid equatorial crossing, the field is weak and can be perturbed by secular variation. While these perturbations are easily lost with smoothing, the early and late stage bias is not. Jumps such as those observed in VGPs paths of some reversals and rebounds indicates that some major changes did occur in the geometry of the field during the transition.

If this explanation is correct, no essential role of smoothing needs to be invoked. This prediction only requires that there be an initial field intensity decrease, caused by the decay of the dipole field, with little, or no associate change in local directions. Evidence that the behaviour of the actual geomagnetic field is similar, is suggested by the recent ingenious analyses of reversal transition records using Zijderveld plots [Mary and Courtillot, submitted]. Here the decrease of the dipole is shown to be accompanied by very little change in direction until the reversal reaches near to the midpoint.

Support for this simple explanation of the distribution of the VGP paths during reversals involving small smoothing comes from the work of Hoffman [1991]. He has shown that lava records of reversals provide evidence for repeated states of the field during reversals, which give VGP's falling within the bands of longitude defined by the sediments and Constable's analysis.

\section{Conclusions}

Simple smoothing of non-antipodal pre- and posttransitional directions [Rochette, 1990] does not provide a general explanation of the observed VGP paths during reversals. For the majority of records, in which the acquisition of magnetization is by a DRM or PDRM process, we therefore conclude that the explanation of these paths is not a simple geometric averaging. This does not rule out the possibility of long termed remagnetization of sediments by viscous remanent magnetization, or by chemical remanence (CRM), or in a more complex case in which secondary authigenic phases result in mixing of components may give high degree of smoothing so that almost all information about the transitional field is lost. From the discussion of the fine structure of the sedimentary records above this is very unlikely the general case.

To summarize, we believe that the observation by Langereis at al. [1992] of the correspondence between the longitude of transition VGP's and the plane containing their "intermediate pre- and post-transition" poles is likely to be explained in terms of the preferred longitudes of VGPs of both reversing and non-reversing field [e. g. Constable, 
1992]. How important smoothing on a time scale shorter than the transition plays an important role is not yet clear.

We therefore retain as a working hypothesis that the preferred longitudes of VGP paths reported are not simply an artefact of the magnetization process. However, we recognize that the demonstration of the fidelity of a particular sedimentary record is a key aspect of modern reversal studies, requiring far more comprehensive documentation than has generally been the case in the past. If such well documented records continue to conform to the pattern we have seen, then it surely cannot be a simple coincidence that the preferred longitudes of the VGP transition paths from sediments are also the longitudes of

(1) preferred VGPs of the recent geomagnetic field [Constable, 1992],

(2) clusters of VGPs of volcanic data from transitions [Hoffman, 1991],

(3) the two principal paired radial flux features in the CMB geomagnetic field [Gubbins and Bloxham, 1987],

(4) the region of NS flow in the outer core [e. g. Laj et al., 1991],

(5) the anomalously fast and hence cold regions in the lower mantle [e. g. Laj et al., 1991].

The problem is now to understand the physics which links these phenomena.

Acknowledgements: We wish to thank C. Langereis for critical reading of the first draft of the manuscript. The coincidence between the preferential bands for VGPs and the anomalously fast regions in the outer core was first pointed out to one of the authors (C. L.) by J. P. Montagner. This work was supported by the CEA and the CNRS. E. H-B was supported by SOEST-HIG and by NSF grants EAR-896597 and EAR-9018270. SOEST-HIG contribution 2988, INSUDBT Instabilités contribution 505, CFR contribution 1331.

\section{References}

Clement, B. M., and Martinson, D. G., A quantitative comparison of two paleomagnetic records of the Cobb Mountain subchron from North Atlantic deep-sea sediments, J. Geophys. Res., 97, 1735-1752, 1992.

Constable, C., Link between geomagnetic reversal paths and paleosecular variation of field over the past $5 \mathrm{Myr}$, Nature, 358, 230-233, 1992.

Creer, K. M., Readman P. W. and Jacobs, A. M., Paleomagnetic and paleontological dating of a section at Gioia Tauro, Italy: identification of the Blake event, Earth Planet. Sci. Lett., 50, 289-300, 1980.

Creer, K. M. and Tucholka, P., Secular variation as recorded in lake sediments: a discussion of North American and European results, Phil. Trans. R. Soc. London, A306, 87-102, 1982.

Gubbins, D. and Bloxham J., Morphology of the geomagnetic field and implications for the geodynamo, Nature, 325, 509-512, 1987.
Herrero-Bervera, E., Helsley, C. E., Hammond, R., and Chitwood, L. A., A possible lacustrine paleomagnetic record of the Blake episode from Pringle Falls, Oregon, USA, Phys. Earth Planet. Int, 56, 112-123, 1989.

Hoffman, K. A., Long-lived transitional states of the geomagnetic field and the two dynamo families, Nature 354, 273-277, 1991.

Laj, C., Mazaud, A., Weeks, R., Fuller, M., HerreroBervera, E., Geomagnetic reversal paths., Nature, 351, 447, 1991.

Laj, C., Mazaud, A., Weeks, R., Fuller, M., HerreroBervera, E., Statistical assessement of the preferred longitudinal bands for recent geomagnetic reversal records, Geophys. Res. Lett., this volume, 1992.

Langereis, C. G., Van Hoof, A. A. M., and Rochette, P., Longitudinal confinement of geomagnetic reversal paths: as a possible sedimentary artefact, Nature, 358, 226-230, 1992.

Larson, E. E., and Walker, T. R., A rock magnetic study of the lower massive sandstone, Moenkopi Formation (Triassic), Gray Mountain Area, Arizona, J. Geophys. Res., 87, 4819-4836-2062, 1982.

Larson, E. E., and Walker, T. R., Comment on "Paleomagnetism of a polarity transition in the lower (?) Triassic Chugwater formation Wyoming", J. Geophys. Res., 90, 2060-2062, 1985.

Mary, C., and Courtillot, V., A new representation of 3-D geomagnetic reversal records: implications for dipolar dominance, Submitted to J. Geophys. Res.

Rochette, P., Rationale of geomagnetic reversals versus remanence recording processes in rocks: a critical review, Earth and Planet. Sci. Lett., 98, 33-39, 1990.

Tric, E., Laj, C., Valet, J.P., Tucholka, P., Paterne, M., and Guichard, F., The blake geomagnetic event: transition geometry, dynamical characteristics and geomagnetic significance, Earth Planet. Sci. Lett., 102, 1-13., 1991.

Tric, E., Valet, J.P., Tucholka, P., Paterne, M., Labeyrie, L., Guichard, F., Tauxe, L., and Fontugne, M., Paleointensity of the geomagnetic field during the last 80,000 years, J. Geophys. Res., 97, 9337-9351, 1992.

Van Hoof, A. A. M., and Langereis, C. G., Reversal records in marine marls and delayed acquisition of remanent magnetization, Nature, 351, 223-225, 1991.

M. Fuller, Department of Geological Sciences, University of California Santa Barbara, CA 93106 USA.

E. Herrero-Bervera, SOEST - HIG, University of Hawaii, Honolulu, HI 96822, USA.

C. Laj, A. Mazaud, R. Weeks, Centre des Faibles Radioactivités, Laboratoire Mixte CNRS-CEA, Avenue de la Terrasse, 91198 Gif-sur-Yvette Cedex, France.

(Received: June 8, 1992

revised: September 8, 1992

accepted: September 10, 1992) 